\title{
La titulatura faraónica de Alejandro Magno: nuevas aportaciones
}

Francisco BOSCH PUCHE

El objetivo de este artículo es presentar un documento procedente del templo erigido en nombre de Alejandro Magno en el oasis de Bahariya y que nunca había sido publicado en detalle con anterioridad. Se trata de un altar de granito rojo cuya inscripción recoge el único testimonio conocido de la existencia de un protocolo onomástico completo para el monarca macedonio. Incluye los cinco nombres que conformaban la titulatura canónica de todo soberano de Egipto.

\section{The Pharaonic titulary of Alexander the Great: new contributions}

This paper presents a document which has never been published in detail before from the temple erected in the name of Alexander the Great at the Bahariya Oasis. It concerns a red granite altar whose inscription provides the sole known attestation of the existence of a complete onomastic protocol for the Macedonian king, with the five names that formed the canonical titulary of all Egyptian rulers.

KEY-wORDs: Bahariya, Alexander the Great, royal titulary

E ntre el otoño de 332 y la primavera de 331 a.C. Alejandro Magno realiza una breve estancia en tierras egipcias. En sólo unos meses el monarca macedonio asume el gobierno del país del Nilo, poniendo fin a la Segunda Dominación Persa, funda la más ilustre de las Alejandrías y efectúa la célebre visita al oráculo de Amón en el desierto libio, que le supone partir hacia la conquista definitiva del Imperio Persa no sólo como soberano de Egipto sino también como "hijo de Zeus". El análisis de la documentación egipcia permite observar cómo el macedonio, hasta su muerte en Babilonia en 323 a.C., se hizo cargo del gobierno del país, al menos de forma nominal. En efecto, existe un protocolo onomástico que le identifica como faraón de Egipto.
El objetivo de este artículo es añadir nuevos datos para el conocimiento de esta titulatura. En primer lugar, realizaremos un breve examen de lo que hasta el momento se conocía de este protocolo $\mathrm{y}$, a continuación, presentaremos un documento que recoge el primer ejemplo conocido hasta el momento de la existencia de un protocolo onomástico completo para Alejandro. Se trata de un altar de granito, localizado en el templo erigido en su nombre en el oasis de Bahariya, en cuya inscripción encontramos por primera vez las cinco designaciones que conformaban la titulatura faraónica canónica en relación con el soberano macedonio.

Es necesario, en primer lugar, señalar el carácter preliminar de los resultados obtenidos

* Agradecemos al Dr. J. Cervelló Autuori la lectura de este texto y sus valiosos comentarios.

Con el apoyo del Departament d'Educació i Universitats de la Generalitat de Catalunya y del Fondo Social Europeo.

Fecha de recepción: 18 de enero de 2007

Fecha de admisión: 15 de mayo de 2007

http://doi.org/10.25145/j.TdE.2009.05.01.08 
que aquí presentamos, ya que, como veremos, la pieza no ha sido hasta el momento localizada y la imposibilidad de cotejar con el original nos obliga a mantener ciertas reservas en la lectura de algunas partes. También cabe puntualizar que el objetivo fundamental de este trabajo es únicamente dar a conocer el documento y no efectuar un análisis detallado del protocolo onomástico de Alejandro en su conjunto, labor que reservamos para nuestra tesis doctoral en curso de elaboración.

\section{El protocolo onomástico de Alejandro Magno: CONOCIMIENTOS PREVIOS}

Al analizar la titulatura real de Alejandro Magno, resulta obligado que nos remitamos a los trabajos de H. Gauthier y J. von Beckerath, obras de referencia en las que se fundamentan todos los estudios onomásticos que se realizan en la actualidad ${ }^{1}$. De estos trabajos se desprende la documentación, para Alejandro, de únicamente tres de los cinco nombres que conformaban el protocolo canónico de los faraones de Egipto: el de Horus, el de entronización o de Rey del Alto y del Bajo Egipto y el de nacimiento o de Hijo de Re. Se trata de una forma abreviada bastante común y que se repite durante la Baja Época².

\subsection{Nombre de Horus}

Para Alejandro Magno disponemos de dos nombres de Horus distintos documentados:

a)

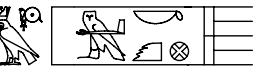

Hrw mk Kmt

Horus, el que protege a Egipto ${ }^{3}$

b)

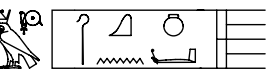

Hrw hqu qni (o hq? nht)

Horus, el gobernante fuerte ${ }^{4}$

Junto con una versión más extensa que añade un epíteto:

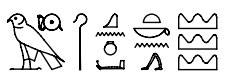

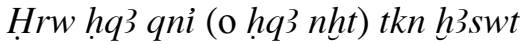

Horus, el gobernante fuerte que ataca ${ }^{5}$ a los países extranjeros ${ }^{6}$

El epíteto $h q 3$ nht únicamente lo tenemos documentado también, aunque con algunas dudas, para Alejandro $\mathrm{IV}^{7}$. Por otra parte, la designación $m k K m t$ es común entre los nombres de Dos Señoras de los soberanos Ramésidas y la reencontramos en una de las denominaciones de Horus de Nectánebo II, último representante de la Dinastía XXX, la última estirpe autóctona anterior a la Segunda Dominación Persa de

[ 104 ] 1. Gauthier, 1916: 199-203; von Beckerath, 1984: 117 y 285. Estos grandes compendios han servido de base a otros trabajos más concretos, entre los que destacan Burstein, 1991; Hölbl, 1992a: 273-274; 2001 [1994]: 79-80; Menu, 1998: 257-258; Sales, 2005: 139-143 y 173-179.

2. Burstein, 1991: 142. Cambises y Darí por ejemplo, también presentan únicamente estos tres nombres. Sobre el protocolo de estos monarcas persas, ver Serrano Delgado, 2001.

3. Capilla de la Barca en el templo de Luxor.

4. Santuario de Alejandro en el Akhmenu de Tutmosis III en el Gran Templo de Amón en Karnak. La lectura alternativa $h q 3$ ?ht la propone Menu, 1998: 258. Ambas lecturas comparten el significado. Con respecto a la traducción también son aplicables otros calificativos como "poderoso", "valiente", etc.

5. Traducción literal: "aproximarse con hostilidad". $W b . \mathrm{V}, 334,7$.

6. Misma localización que el anterior.

7. Von Beckerath, 1984: 117 y 286. 
Egipto. En una variante extensa del nombre de Dos Señoras de este último, también se incluye el epíteto $t k n h 3 s w t^{8}$.

\subsection{Nombre de Rey del Alto y del Bajo Egipto}

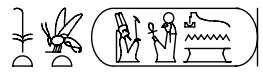

Ésta es la forma habitual del nombre de entronización de Alejandro Magno9. Tradicionalmente, la lectura que se ha ofrecido de esta designación ha sido $n s w t$-bity stp-n-R` mri-Imn, "Rey del Alto y del Bajo Egipto, el elegido de Re y amado de Amón"10. H. de Meulenaere, sin embargo, en un artículo dedicado al estudio del protocolo real de Filipo Arrideo, sucesor de Alejandro, que en Tebas presenta el mismo nombre de entronización que su predecesor, desarrolla un método de lectura que le lleva a concluir la necesidad de invertir los elementos: nswt-bity stp-n-Imn mri$R{ }^{c}$, "Rey del Alto y del Bajo Egipto, el elegido de Amón y amado de Re"11. Pero existe un gran número de variantes gráficas de este nombre ${ }^{12}$, algunas de las cuales, como por ejemplo la que sigue a continuación ${ }^{13}$, infringen las pautas de lectura establecidas por este autor. Consciente de ello, éste se ve obligado a aceptar la existencia de numerosas excepciones, que considera anomalías o atribuye a la negligencia o a causas desconocidas $^{14}$, sin zanjar definitivamente la cuestión.

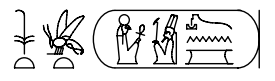

A raíz de las apreciaciones de H. de Meulenaere, pero sin descartar la lectura tradicional, hoy en día distintos autores como G. Hölbl optan por referir la posible doble lectura ${ }^{15}$. En un futuro, cabe profundizar sobre este tema para determinar hasta qué punto se trata de una sola variante con una única lectura, una sola variante que admite una doble lectura o bien dos variantes distintas (dos nombres), formadas a partir de los mismos elementos ${ }^{16}$.

Disponemos, también, de otro nombre de entronización distinto para Alejandro. Se trata de una variante irregular y muy poco frecuente ${ }^{17}$ que utiliza el antropónimo del soberano macedonio. En este caso nos encontramos ante algo excepcional y sin paralelos conocidos ${ }^{18}$.

8. Hölbl, 1992a: 273; 2001 [1994]: 79. Los ejemplos que vinculan a Alejandro con los integrantes de la Dinastía XXX y en especial con Nectánebo II son frecuentes. Además de en el protocolo onomástico, encontramos también elementos de unión en el programa arquitectónico que se desarrolla en nombre del soberano macedonio, pues en muchos casos se retoman obras iniciadas por la última dinastía indígena pero detenidas en tiempos del dominio persa. Especial mención merece, en este sentido, la llamada "historia de Nectánebo" recogida en la Novela de Alejandro del PseudoCalístenes (I, 1-14). Este relato, que proviene de una leyenda popular de origen egipcio, nos presenta a Alejandro como hijo de Nectánebo II y, por extensión, como heredero legítimo al trono del país. Sobre este relato y sus implicaciones ideológicas, ver Lloyd, 1982: 46-50.

9. Entre otros lugares, la encontramos en la Capilla de la Barca en el templo de Luxor, la puerta de entrada del IV pilono del Gran Templo de Amón en Karnak y la puerta de entrada del pilono del templo de Khonsu también en Karnak.

10. Por ejemplo así von Beckerath, 1984: 117.

11. De Meulenaere, 1991: 54-57. Seguido por Menu, 1998: 258. Debido a que el cartucho comporta la presencia de dos dioses y de dos elementos complementarios (por ejemplo, dos participios pasivos como en este caso), el primer elemento debe ser vinculado a la primera divinidad y el segundo de ellos, a la segunda.

12. La mayor parte de ellas recogidas por Gauthier, 1916: 200-202; von Beckerath, 1984: 285.

13. Fragmento de clepsidra procedente de Tell el-Yahudiya en el British Museum (EA 933). Existen otras variantes similares en Luxor y Karnak.

14. De Meulenaere, 1991: 56, nota 31.

15. Hölbl, 1992a: 274; 2001 [1994]: 79-80.

16. Esta última es la posibilidad que, de momento, consideramos la más plausible y en la que estamos trabajando para intentar resolver definitivamente este asunto. 


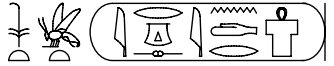

nswt-bity Irgsindrs

Rey del Alto y del Bajo Egipto, Alejandro

\subsection{Nombre de HiJo de RE}

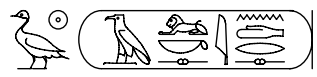

s3 $R$ ? $3 r k s i n d r s$

Hijo de Re, Alejandro ${ }^{19}$

Como es habitual en monarcas extranjeros, con el nombre de nacimiento de Alejandro simplemente se opta por adaptar a la fonética egipcia y transcribir

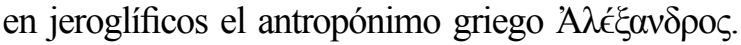
Existe un gran número de variantes ortográficas de esta designación, normalmente relacionadas con la elección de los signos jeroglíficos utilizados (debido a su proximidad o equivalencia fonética) y con su disposición en el interior del cartucho ${ }^{20}$.

\section{El altar del templo de Alejandro Magno en BAHARIYA}

Una vez examinado brevemente lo que hasta el momento se conocía en torno a la titulatu- ra faraónica de Alejandro Magno, dedicaremos esta segunda parte al análisis de un documento que, como ya hemos anunciado, se erige como fundamental para el estudio del inicio de la dominación griega de Egipto y, en especial, en relación con el reinado del monarca como faraón, pues recoge el primer ejemplo conocido hasta el momento de la existencia de un protocolo onomástico completo para el soberano macedonio.

En 1938 A. Fakhry descubrió un pequeño templo erigido en nombre de Alejandro en el oasis de Bahariya ${ }^{21}$. Los trabajos de excavación, que se prolongaron hasta 1945 , sacaron a la luz un pequeño recinto cultual dedicado a Amón- $\mathrm{Re}^{22}$, que se mantuvo en uso como lugar de culto hasta Época Romana ${ }^{23}$ y, después, como zona de habitación hasta el s. XII ${ }^{24}$ (figuras 1-2).

El documento que nos concierne fue localizado tumbado delante de la puerta de entrada al recinto. Se trata de un altar que presumiblemente habría estado situado en origen en el interior del santuario. La única descripción de la pieza la encontramos en el segundo volumen que A. Fakhry dedicó a la presentación de los trabajos efectuados y de los restos documentados en el oasis de Bahariya. Brevemente nos dice que se trata de un altar de granito rojo, de forma tron-

17. Dos son los ejemplos que conocemos hasta el momento, aunque no descartamos que pueda existir algún otro. La variante que aquí incluimos proviene del interior de la Capilla de la Barca en el templo de Luxor. El otro ejemplo, con una variante ortográfica distinta, también se documenta en Luxor, concretamente en un grafito en el muro exterior del ángulo noroeste del gran patio porticado erigido por Amenhotep III

18. No se conoce ningún otro caso de utilización del nombre propio como designación de Rey del Alto y del Bajo Egipto. Por otra parte, los ejemplos de reyes con más de un nombre de entronización son muy escasos; además de Alejandro, disponemos únicamente de otros tres ejemplos: Akhenatón, Siptah y Peye. Ver Burstein, 1991: 143-144.

19. Entre otros, el santuario de Alejandro en el Akhmenu de Tutmosis III en el Gran Templo de Amón en Karnak y un fragmento de clepsidra procedente de Tell el-Yahudiya en el British Museum (EA 933).

20. Algunas de ellas recogidas por Gauthier, 1916: 200-202; von Beckerath, 1984: 285. Aunque existen muchas otras.

21. Fakhry, 1939: 638-639 y láms. 118-119a.

22. Fakhry, 1941; 1950: 41-47 y láms. 24-35; 1974: 65 y 99-103. También Aufrère, Golvin y Goyon, $1994: 136$ y 137 (propuesta de restitución).

23. Colin, 1997: especialmente 94-95.

24. Fakhry, 1950: 47; 1974: 100-101. 


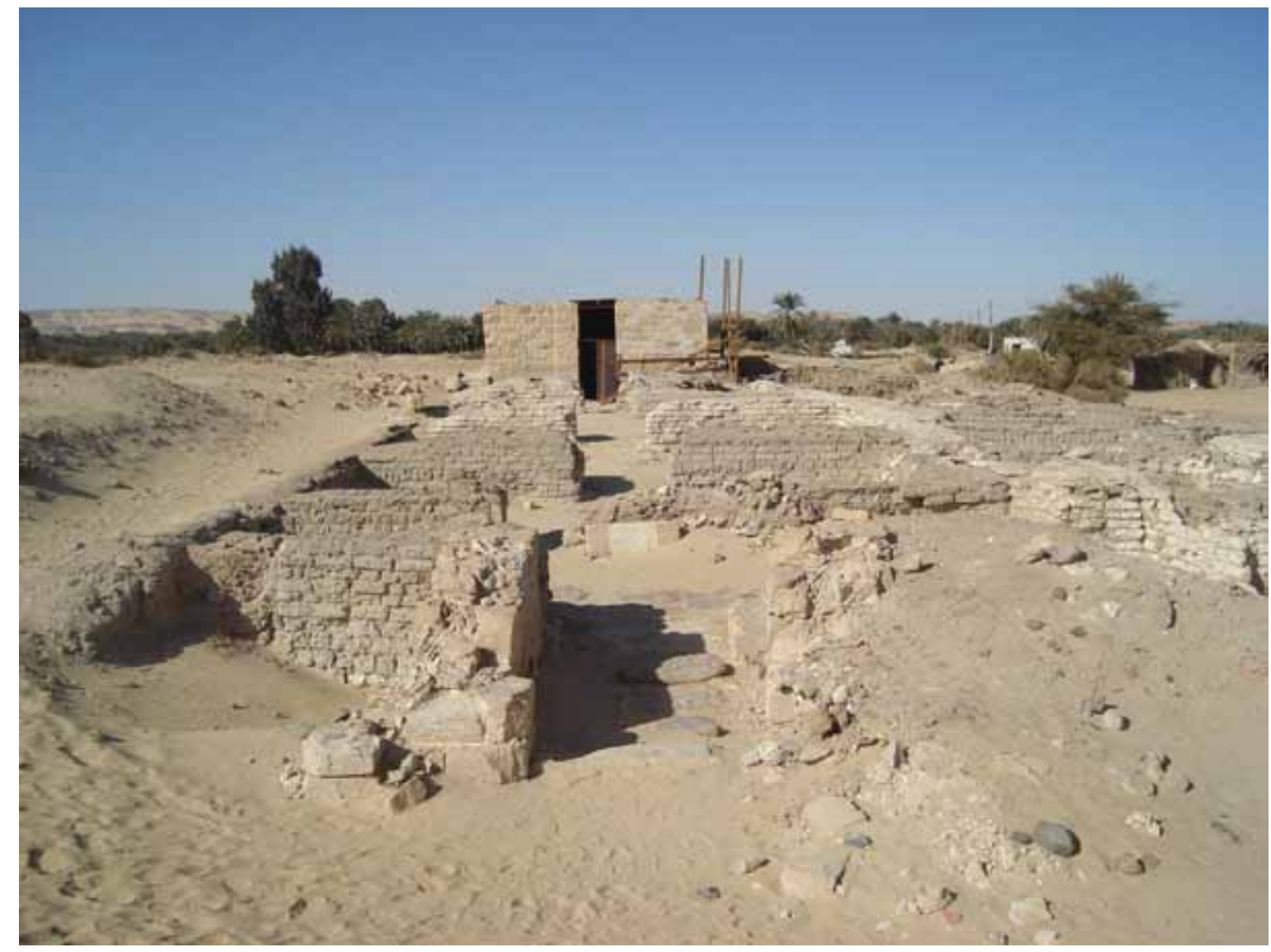

Figura 1. El templo de Alejandro Magno en Bahariya en la actualidad (Fotografía: F. Bosch Puche)

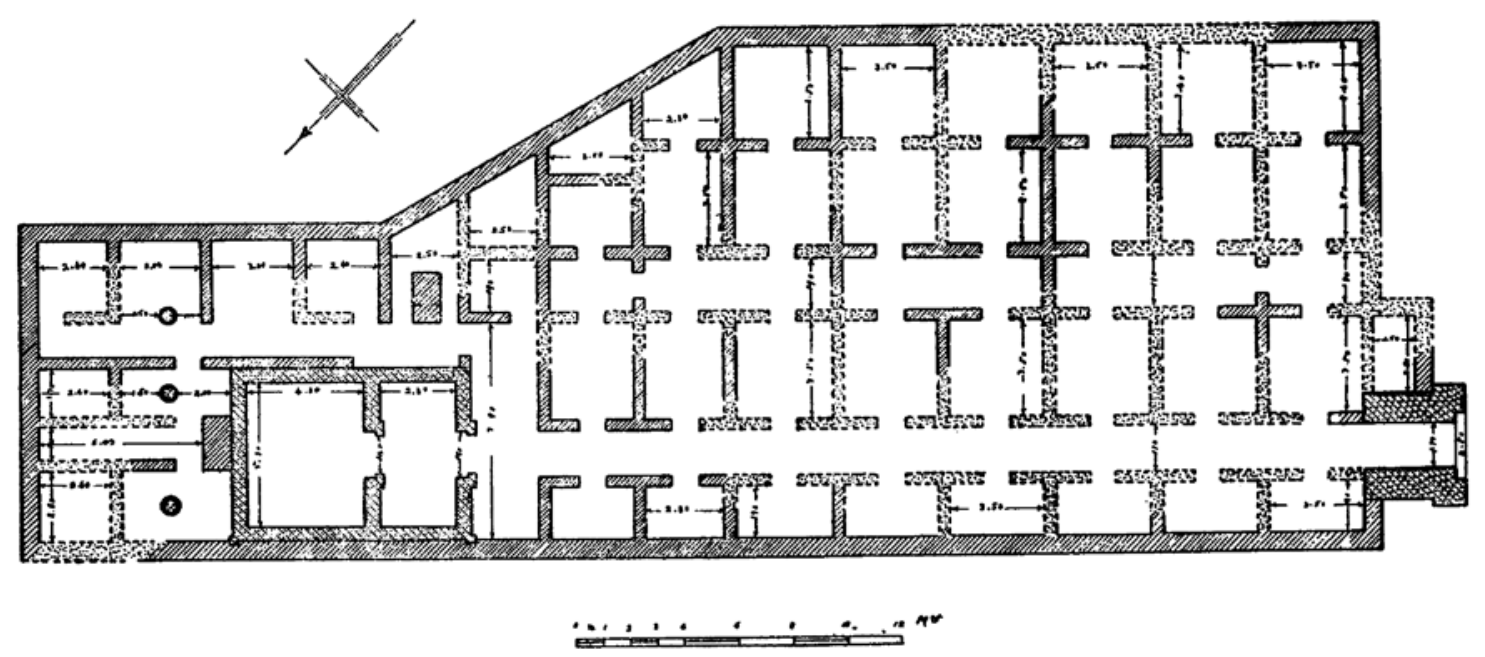

Figura 2. Planta del templo de Alejandro (Fakhry, 1950: 43, fig. 29) 
copiramidal, $109 \mathrm{~cm}$ de altura (tronco de $99 \mathrm{~cm}$ + cornisa de $10 \mathrm{~cm}$ ), base cuadrada de $25 \mathrm{~cm}$ de lado y parte superior también cuadrada de 18 $\mathrm{cm}$ de lado. Una de las cuatro caras está inscrita; presenta una columna de texto que continúa en otra a su izquierda de menor longitud. La anchura de la caja de escritura es de $6 \mathrm{~cm}$ y la orientación del texto es de derecha a izquierda. El autor afirma que reserva la publicación del texto y su comentario para un tercer volumen de la serie (volumen que nunca existió), pero que de momento incluye una fotografía suficientemente buena (figura 3$)^{25}$. Esta fotografía es la única imagen que existe de la pieza. Después de esto, toda referencia al altar desaparece hasta 1974, un año después de la muerte de A. Fakhry, cuando aparece publicado póstumamente el segundo volumen de la serie The Oases of Egypt, dedicado a los oasis de Bahariya y Farafra. En él, el autor añade que el altar incluye el nombre de Alejandro y que "éste ahora está en el Museo de El Cairo"26.

En el último año, hemos intentado localizar la pieza, pero sin éxito. El altar no aparece en el Journal d'Entrée ni en ningún otro registro del museo. Sus conservadores no tenían constancia de la existencia de la pieza y hasta el momento no ha aparecido por ninguna parte. Cabe esperar que haya suerte y que se encuentre olvidado en algún rincón del basement del museo, aunque no todo el mundo se muestra igual de optimista ${ }^{27}$. Este hecho nos ha obliga[ 108 ] do a trabajar con la única fuente disponible, la fotografía que acabamos de mencionar. Por este motivo, y como ya ha sido señalado al inicio, no podemos tomar la lectura que aquí ofrecemos

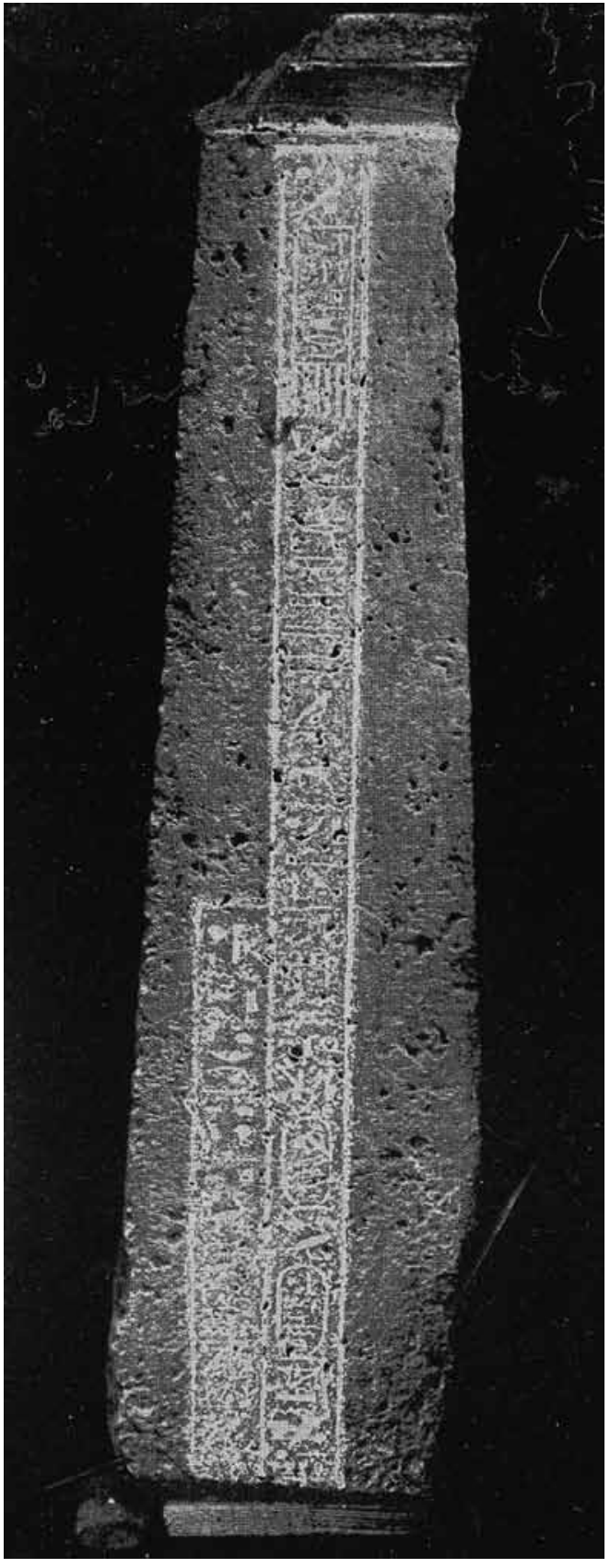

Figura 3. El altar del templo de Alejandro (Fakhry, 1950: lám. 26)

25. Fakhry, 1950: 46-47 y lám. 26.

26. Fakhry, 1974: 100.

27. Aprovechamos para expresar nuestro más sincero agradecimiento al equipo técnico del museo por la ayuda ofrecida y los esfuerzos que está dedicando para localizar el altar. Especial mención merece, en este sentido, la Sra. Sabah Abdel Razek, conservadora responsable del basement.

28. Nos hemos servido de distintos medios técnicos para facilitar nuestro trabajo, en especial varios programas informáticos de tratamiento de imágenes. 
como definitiva, sino más bien como una primera aproximación que espera ser confirmada y completada una vez pueda ser cotejada con la pieza original ${ }^{28}$.

\subsection{Primera columna}

La primera columna de texto del altar recoge el primer ejemplo conocido hasta el momento de protocolo onomástico completo para Alejandro Magno. El texto nos ofrece las cinco designaciones que conforman la titulatura faraónica en su orden canónico y supone la primera documentación de los nombres de Dos Señoras y de Horus de Oro en relación con el soberano macedonio.

\subsubsection{Nombre de Horus}

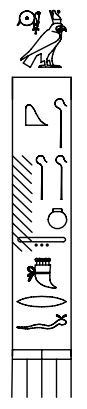

Hrw $h q 3 h q 3 w n w t 3(r) \underline{d} r=f$

Horus, el gobernante de los gobernantes de la tierra entera

Escrito en el interior del serekh, nos hallamos ante un nuevo nombre de Horus para Alejandro, que se añade a los dos que ya se conocían. H. de
Meulenaere, en el artículo referido más arriba y dedicado al estudio del protocolo real de Filipo Arrideo, ya había reparado en la existencia de esta nueva designación inscrita sobre el altar, a pesar de que la lectura que ofrece no es del todo exacta $^{29}$.

Su paralelo más claro y cronológicamente más cercano lo constituye el nombre de Horus de Oro de Alejandro IV, hijo de Alejandro Magno y Roxana: $h q$ 3 ( $n h t$ ?) $m t 3$ ( $r) \underline{d} r=f$, "el gobernante (fuerte?) en la tierra entera" ${ }^{30}$. Por otra parte, cabe señalar que la designación $h q 3 h q 3 w$, como parte integrante de las titulaturas reales, no es algo común. El único precedente lo encontramos en uno de los nombres de Horus de Amenhotep III, donde aparece como epíteto de la designación habitual de $k 3 n h t$, "toro fuerte" 31 . No lo encontraremos de nuevo hasta Época Romana, como epíteto en los nombres de Horus de Augusto, Tiberio y Nerón y en alguno de los nombres de entronización también de Augusto y Nerón, así como de Calígula y Claudio ${ }^{32}$. Las implicaciones de este último hecho son, a nuestro entender, fundamentales, porque de todos es conocida la voluntad de los emperadores romanos, y muy especialmente de Augusto, de emular a Alejandro. Como consecuencia, la utilización de este epíteto en las denominaciones faraónicas de todos los miembros de la dinastía Julio-Claudia, más que una simple casualidad, podría ser considerada como una prueba más de esta voluntad de establecer lazos de unión, desde un punto de vista ideológico, con la figura del soberano macedonio ${ }^{33}$.

29. De Meulenaere, 1991: 53, nota 2. El autor, por una parte, obvia la presencia del genitivo y reseña la fórmula habitual con $m$ de lugar; y, por otra, señala la presencia de $r$ que, en realidad y como es habitual, aquí se omite. Sorprendentemente, de Meulenaere no hace ninguna otra referencia al resto del protocolo recogido en la inscripción.

30. Von Beckerath, 1984: 117 y 286.

31. Von Beckerath, 1984: 85-86 y 229.

32. Von Beckerath, 1984: 123-124 y 296-299.

33. Parece que Augusto se vincula directamente a Alejandro, prescindiendo de los Ptolomeos. En este sentido, ver las apreciaciones de Hölbl, 1992a: 277; 1992b: sobre todo 49. 


\subsubsection{Nombre de Dos Señoras}

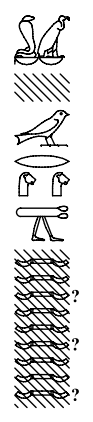

\section{Nbty [...] wr phty ițỉ [psd $t$ t-p $\underline{d} t(?)]$}

Las Dos Señoras, [...], grande de fuerza, el que conquista [los Nueve Arcos(?)]

El nombre de Dos Señoras de Alejandro se compone de tres epítetos. Hasta hoy, la lectura del primero de ellos constituye todavía para nosotros una incógnita, pues no hemos sido capaces de determinar con seguridad el o los signos que lo componen ${ }^{34}$.

En segundo lugar, la designación "grande de fuerza" aparece documentada por primera vez en la Dinastía XVIII y la encontramos mayormente asociada al nombre de Horus hasta la Dinastía XX, aunque no es muy frecuente. Después prácticamente desaparece hasta Época Grecorromana, donde la reencontramos formando parte sobre todo de los nombres de Horus, pero también de Dos Señoras y de Horus de Oro, de los Ptolomeos y los primeros emperadores $^{35}$.
Finalmente, con respecto al tercer epíteto, debemos indicar en primer lugar que, hasta que no podamos cotejar la única fotografía existente del documento con la pieza original, la referencia a los "Nueve Arcos" es hipotética y debe entenderse como una propuesta por verificar, puesto que lo único que se aprecia con claridad es la presencia de una serie de signos horizontales. Tampoco la utilización del participio activo iți nos sirve de mucha ayuda en este sentido, pues no se trata de un verbo habitual acompañando a los "Nueve Arcos" (como lo serían $h w i^{36}, d r^{37} \mathrm{y}$, en menor medida, también $\left.w^{f} f^{38}\right)$ y, en los ejemplos disponibles hasta el momento, el objeto es siempre $t 3 w n b w$, "todas las tierras / países"39, o alguna forma equivalente.

Según parece, con esta designación se habría pretendido señalar la imposición total del dominio del faraón en el mundo entero y, en especial, sobre todas las naciones extranjeras de la tierra, o lo que es lo mismo, sobre los enemigos de Egipto. Variantes de este epíteto son utilizadas con profusión en las titulaturas reales. Con anterioridad, las encontramos formando parte del nombre de Horus de Oro de algunos Tutmósidas. En Época Ramésida su uso es muy habitual y están presentes, además de en el de Horus de Oro, también en el de Dos Señoras. Posteriormente su utilización decae, aunque sin llegar a desaparecer, y las encontramos de nuevo restringidas sólo al nombre de Horus de

34. Que ocupan un único cuadro.

35. Síntesis evolutiva de la frecuencia de uso de este epíteto deducida a partir de von Beckerath, 1984. Existen variantes de este epíteto, formadas con adjetivos distintos, cuyo significado es el mismo o muy parecido y que también se documentan abundantemente.

36. "Golpear". $W b$. III, 46, 8-9.

37. "Expulsar, someter / vencer, matar". $\mathrm{Wb}$. V, 473, 4 y 474, 5-6.

38. "Conquistar, derrotar/ vencer". $W b$. I, 285, 7 y 10.

39. Así en uno de los nombres de Dos Señoras de Tutmosis I (von Beckerath, 1984: 83-84 y 225) y en uno de los de Horus de Oro de Osorcón I (101 y 258).

40. Sí que existe, sin embargo, una referencia a los "Nueve Arcos". Concretamente se trata del epíteto $h r y-t p-p s \underline{d} t-p \underline{d} t$, "jefe de los Nueve Arcos", incluido en uno de los nombres de Horus de Ptolomeo VIII. Ver von Beckerath, 1984: 120 y 291. Síntesis evolutiva de la frecuencia de uso de las distintas variantes de esta designación deducida a partir de von Beckerath, 1984. 
Oro. En Época Grecorromana no disponíamos, hasta ahora, de ninguna documentación de esta designación ${ }^{40}$.

\subsubsection{Nombre de Horus de Oro}

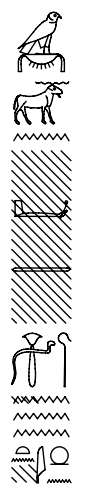

Hrw nbw b3 $n[\ldots] h q 3$ w $3 \underline{d}(-w r)$ šnw $n$ itn

Horus de Oro, el $b a$ de [...], el gobernante del mar y de lo que el sol rodea ${ }^{41}$

El nombre de Horus de Oro es el que ofrece un mayor número de problemas. Ésta es la parte de la inscripción, junto con el extremo final de ambas columnas, que más interrogantes nos plantea, a pesar de no tratarse de uno de los fragmentos peor conservados. Hasta el momento, no hemos podido aclarar lo que aparece escrito. Las limitaciones de espacio y el carácter excesivamente preliminar de las hipótesis que barajamos nos impiden detenernos en este punto. Preferimos esperar a la aparición de la pieza y no extendernos con una larga lista de probabilidades que, en muchos casos, no son más que simples conjeturas. Sólo remarcaremos que, en vista de los paralelos exis- tentes, cabría esperar que, después de la referencia al $b a$, nos encontráramos con el nombre de una divinidad $^{42}$, acompañado por uno o dos epítetos, a tenor del espacio disponible ${ }^{43}$. Estos epítetos harían referencia bien a esta divinidad bien a Alejandro, opción más probable, constituyendo en este último caso una designación independiente dentro del nombre.

El epíteto final, bastante legible, constituye un elemento excepcional, pues se trata de una designación que no dispone de paralelos conocidos en los protocolos onomásticos reales. Con él se señala el dominio de Alejandro por tierra y por mar, es decir, en el mundo entero, a imagen y semejanza de alguno de los dioses más importantes del panteón egipcio ${ }^{44}$.

\subsubsection{Nombre de Rey del Alto y del Bajo Egipto}

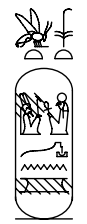

nswt-bity stp-n-R` [mri]-'Imn

Rey del Alto y del Bajo Egipto, el elegido de Re y [amado] de Amón

La evidente presencia de los cartuchos ya había sido señalada con anterioridad por distintos autores, aunque nunca antes habían sido analizados en detalle. Con respecto al primero de ellos, que recoge el nombre de entronización de

41. Es decir, "el mundo". $W b$. IV, 490, C.I-II y 493, V.

42. Estos paralelos siempre presentan a Re. Así, por ejemplo, en uno de los nombres de Horus y en las distintas variantes del nombre de entronización de Mineptah. Ver von Beckerath, 1984: 91 y 239-240.

43. Tres cuadros en total.

44. Como por ejemplo Osiris, entre cuyos epítetos encontramos el que aquí nos ocupa, aunque en la forma de dos designaciones independientes. Ver Leitz, 2003: VIII, 145, 156 y 171-172.

45. Fakhry, 1941: 826-827; 1950: 45-46. Estos paralelos son los que nos han llevado a restituir con seguridad el signo del canal (N36) en el extremo final del cartucho que, debido al mal estado de conservación, aquí es prácticamente inapreciable. 
Alejandro, poco podemos añadir a lo que ya se conocía y que ha sido mencionado más arriba. Se trata de una de las dos variantes o lecturas comunes de esta designación del soberano macedonio y con una grafía de la que disponemos un gran número de paralelos, algunos de los cuales proceden del mismo templo de Alejandro en Bahariya ${ }^{45}$.

\subsubsection{Nombre de Hijo de Re}

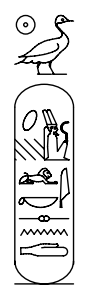

\section{s3 $R^{\complement}$ s3-Imn Irks(i)nd(rs)}

Hijo de Re, el hijo de Amón, Alejandro

El segundo cartucho contiene una grafía defectiva del antropónimo "Alejandro". Esto parece ser algo propio de Bahariya, pues los otros dos ejemplos del nombre de nacimiento de Alejandro que A. Fakhry documentó en las inscripciones del santuario también carecen de algunos signos, aunque distintos a los que faltan aquíi ${ }^{46}$ :

$$
\begin{aligned}
& s^{3} R^{\complement} \operatorname{Irk}[s] i(n) d r s^{47} \\
& {[\ldots] \operatorname{Ir}(k) s(\text { in }) d r s^{48}}
\end{aligned}
$$

El nombre de Alejandro se encuentra precedido por el epíteto "hijo de Amón"49. Esta inclusión también es nueva y fundamental, pues nos remite a los resultados de la visita de Alejandro al oráculo de Amón en el desierto libio: el reconocimiento de su filiación divina por parte de la divinidad ${ }^{50}$.

\subsubsection{Final de la columna}

Como conclusión al protocolo, en el extremo final de la columna, parece que nos encontramos con la fórmula habitual:

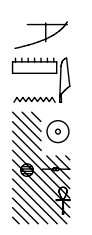

$$
\begin{aligned}
& \text { mri Imn- } R^{\complement}[\ldots] \\
& \text { Amado de Amón Re, }[\ldots]
\end{aligned}
$$

Este primer epíteto, que no se presenta en inversión respetuosa, como cabría esperar, está acompañado de una serie de signos de menores dimensiones y lectura hasta el momento incierta ${ }^{51}$. En toda esta parte, el altar parece haber sufrido importantes golpes que dificultan la lectura de la inscripción; como consecuencia, una vez más, la aparición del documento original sería de gran ayuda para disipar las dudas existentes.

46. Variantes no recogidas por von Beckerath, 1984: 117 y 285.

47. Falta $n$. Ver Fakhry, 1941: 826; 1950: 45.

48. Faltan $k$, la segunda $i$ y $n$. Ver Fakhry, 1941: 827; 1950: 46.

49. No descartamos que esta misma designación pudiera haber estado presente en la laguna inicial del segundo ejemplo del nombre de nacimiento de Alejandro documentado por A. Fakhry y que acabamos de mencionar. Gauthier (1916: 202, núm. XV) también recoge otra variante precedida por este epíteto y cita: "M. Budge (Book of the Kings, II, p. $108)$, sans référence". La confirmación de estos dos testimonios dudosos en cierta medida probaría que la utilización de esta variante pudo haber sido más generalizada.

50. Éste es el episodio de la breve estancia de Alejandro Magno en territorio egipcio tratado de manera más amplia y detallada por el conjunto de la tradición clásica: Diodoro, XVII, 49.2 - 51; Curcio, IV, 7.5-32; Plutarco, Vida de Alejandro, 26.11 - 27; Arriano, III, 3 - 4; Justino, XI, 11.2-12; Estrabón, XVII, 1.43. También entre los historiadores actuales las motivaciones y consecuencias de la visita al oráculo continúan constituyendo un importante elemento de discusión; ver, por ejemplo, Langer, 1981; Anson, 2003.

51. La disminución del tamaño de los signos probablemente se explica por las limitaciones de espacio debido a su ubicación en el extremo de la pieza. 


\subsection{Segunda columna}

En la segunda columna de texto del altar encontramos una referencia al sacerdote que presumiblemente dedica la pieza. Su contenido ya ha sido objeto de estudio con anterioridad. Fue examinado por F. Colin en un artículo dedicado al estudio de un grafito griego grabado en la puerta de entrada del recinto del templo. El autor, que sin embargo pasa de largo por la primera columna de texto, hace referencia a esta inscripción con el fin de corroborar la dedicación del santuario a Amón-Re ${ }^{52}$.

Ésta es su propuesta:

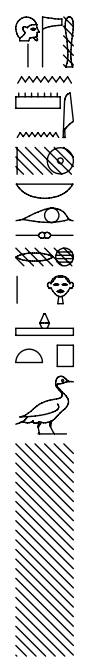

hlm-ntr tpy n Imn-Re nb irt shr Hr-htp s3 [...] El primer profeta de Amón-Re, señor de la ejecución de los planes, Herhotep, hijo de $[\ldots]^{53}$
A la lectura de F. Colin, con la que coinci$\operatorname{dimos}^{54}$, podemos añadir algo más. A pesar de que, en la mitad inferior de la columna, el texto se encuentra en muy mal estado, se intuyen algunos signos más, siempre con la máxima reserva $^{55}$ :

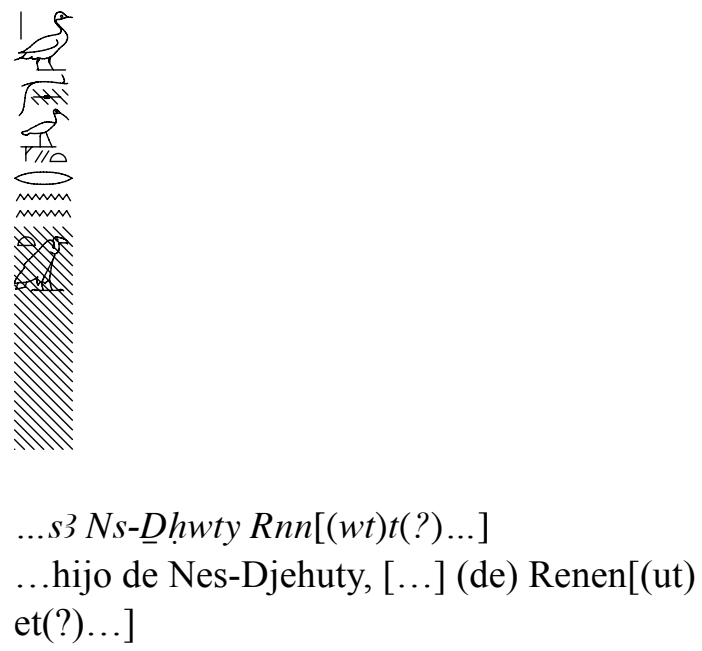

Nos hallaríamos, pues, ante una referencia al padre del personaje. Después del antropónimo, un nombre teóforo de Tot ya documentado con anterioridad $^{56}$, encontramos una mención a Renenutet ${ }^{57}$. La lectura del contenido restante del extremo final de la columna es más problemático, así como la determinación de su relación con el nombre de la diosa ${ }^{58}$. Podríamos pensar en la posibilidad que en la laguna final estuviera escrito el título sacerdotal del personaje, pues regiría la inversión respetuosa, y que el

52. Colin, 1997.

53. Colin, 1997: 95 y fig. 3.

54. A su transcripción en jeroglíficos reduciríamos las dimensiones del primer sustantivo e incluiríamos un trazo vertical (Z1) acompañando el pato G39, de acuerdo con la grafía habitual del sustantivo "hijo".

55. Estrictamente, el mal estado de esta parte de la inscripción y las dudas que aún albergamos nos obligarían a tramar totalmente el texto, pero para no incomodar la lectura en exceso, hemos optado por hacerlo simplemente con las partes más dudosas y maltrechas.

56. Ranke, 1935: I, 180, 1.

57. Parece que la grafía del nombre de la divinidad presenta el buitre (G14) como determinativo, en posible alusión a su carácter nutricio. No hemos podido documentar, sin embargo, ningún paralelo de este teónimo determinado con este signo. Para las variantes más comunes, ver $W b$. II, 437; Leitz, 2002: IV, 686.

58. Que ocupa una extensión de tres cuadros. 
espacio inmediatamente anterior lo ocupara alguno de sus epítetos o, incluso, un topónimo ${ }^{59}$, aunque sin la aparición de la pieza cualquiera de estas hipótesis permanece pendiente de confirmación.

\section{Conclusiones}

Para finalizar sólo nos queda reiterar la importancia de este altar, que hasta hoy se había mantenido prácticamente olvidado, porque recoge el primer ejemplo conocido de protocolo onomástico completo para Alejandro Magno como faraón de Egipto. Un protocolo formado por: un nuevo nombre de Horus, que se añade a los ya recogidos en los repertorios existentes; el primer (y único) ejemplo de nombre de Dos Señoras; la primera (y única) documentación, también, del nombre de Horus de Oro; un ejemplo más de una versión ya conocida del nombre de entronización; y una nueva variante del nombre de nacimiento que incluye, en el interior del cartucho, el epíteto "hijo de Amón", precediendo al antropónimo del soberano.
A pesar de que los resultados obtenidos y que acabamos de presentar no son definitivos, ya que la imposibilidad de cotejarlos con la pieza original nos obliga a mantener ciertas reservas en la lectura, un documento de estas características supone la apertura de toda una serie de nuevas vías de estudio. El altar procedente del templo erigido en nombre de Alejandro en el oasis de Bahariya añade nuevos y trascendentales datos en relación con la onomástica del soberano macedonio y obliga a replantear cualquier formulación que, en torno a cuestiones de ideología y de legitimación real derivadas de ésta, se hayan podido efectuar con anterioridad.

Nota: Con posterioridad a la presentación de nuestra comunicación en el III Congreso Ibérico de Egiptología y durante el proceso de edición del presente artículo, el documento de Bahariya fue finalmente localizado en el basement del Museo Egipcio de El Cairo. En relación con su publicación, ver BoschPuche, F. (2008): L'«autel» du temple d'Alexandre le Grand à Bahariya retrouvé, BIFAO 108: 29-44. Aunque este estudio ulterior de la pieza supera el análisis preliminar que aquí acabamos de presentar, hemos optado por respetar la versión original de éste, sin modificaciones, para así dejar constancia del desarrollo de la investigación.

59. En este sentido es interesante señalar que el primer signo del fragmento peor conservado podría ser M24: $r s y$, "el sur". También se distingue un animal: un pájaro o, tal vez, el cocodrilo Sobek. Esta última posibilidad es la más sugerente, pues el conjunto podría aludir al Fayum. En efecto, entre las designaciones del oasis encontramos: $\breve{S}$ rsy, "el lago meridional", e incluso $\breve{S} r s y n$ Sbk, "el lago meridional de Sobek" (Hannig, 1995: 1386. Otras designaciones del oasis también incluyen el nombre de la divinidad; ver Hannig, 1995: 1387). Además, el Fayum, concretamente Medinet Madi (la egipcia Dja y griega Narmuthis), albergó el principal santuario de la diosa, también dedicado a Sobek y a Horus. Sobre la diosa Renenutet y su templo, ver las síntesis de Wilkinson, 2002 [2000]: 137; 2003: 225-226. En relación con la divinidad, ver también Leitz, 2002: IV, 686-692. 


\section{Bibliografía}

ANSON, E.M.

2003 Alexander and Siwah, AncW 34: 117-130.

Aufrère, S.; Golvin, J.-C.; Goyon, J.-C.

1994 L'Égypte restituée. Tome 2: Sites et temples des déserts. De la naissance de la civilisation pharaonique à l'époque grécoromaine. Paris.

BECKERATH, J. VON

1984 Handbuch der ägyptischen Königsnamen. (MÄS 20). München / Berlin.

BuRSTEIN, S.M.

1991 Pharaoh Alexander: A Scholarly Myth, AncSoc 22: 139-145.

Colin, F.

1997 Un ex-voto de pèlerinage auprès d'Ammon dans le temple dit «d'Alexandre», à Bahariya (désert Libyque), BIFAO 97: 91-96.

ERman, A.; Grapow, H.

1982 Wörterbuch der ägyptischen Sprache. Berlin, 12 vols.

FAKHRY, A.

1939 Bahria and Farafra Oases. Second Preliminary Report on the New Discoveries, ASAE 39: 627-642 y pl. CXII-CXXI.

1941 A Temple of Alexander the Great at Bahria Oasis, $A S A E$ 40: 823-828 y pl. CX-CXIII.

1950 The Egyptian Deserts: Bahria Oasis, vol. II. Cairo.

1974 The Oases of Egypt. Vol. II: Bahrîyah and Farafra Oases. Cairo.

GaUthier, $\mathrm{H}$.

1916 Le livre des rois d'Égypte. Recueil de titres et protocoles royaux, noms propres de rois, reines, princes, princesses et parents de rois, suivi d'un index alphabétique. Vol. IV: De la XXVe dynastie à la fin des Ptolémées. (MIFAO 20). Le Caire.
HANNIG, R.

1995 Die Sprache der Pharaonen: Großes Handwörterbuch Ägyptisch - Deutsch (2800-950 v. Chr.). (Kulturgeschichte der antiken Welt 64). Mainz.

HöLBL, G.

1992a Königliche Legitimität und historische Umstände im Spiegel der pharaonischen Titulaturen der griechisch-römischen Zeit - Einige Interpretationen und Diskussionsvorschläge, en: Sesto Congresso Internazionale di Egittologia, Atti. Torino, vol. I, 273-278.

1992b Zum Titel $h q 3 \quad h q 3 w$ des römischen Kaisers, GM 127: 49-52.

2001 A History of the Ptolemaic Empire. London / New York (ed. orig. 1994, Darmstadt).

LANGER, P.

1981 Alexander the Great at Siwah, $A n c W$ 4: 109-127.

Leitz, C. (ED.)

2002-2003 Lexikon der ägyptischen Götter und Götterbezeichnungen. (OLA 110-116 y 129). Leuven / Paris / Dudley, 8 vols.

Lloyd, A.B.

1982 Nationalist Propaganda in Ptolemaic Egypt, Historia 31: 33-55.

Meulenaere, H. DE

1991 Le protocole royal de Philippe Arrhidée, CRIPEL 13: 53-58.

Menu, B.

1998 Le tombeau de Pétosiris (4). Le souverain de l'Égypte, BIFAO 98: 247-262.

RANKE, $\mathrm{H}$.

1935, 1952, 1977 Die ägyptischen Personennamen. Glückstadt, 3 vols. 
SALES, J. D. C.

2005 Ideologia e propaganda real no Egipto ptolomaico (305-30 a.C.). Lisboa.

Serrano Delgado, J.M.

$2001 \mathrm{La}$ titulatura real de los faraones persas, en: Cervelló Autuori, J.; Quevedo Álvarez, A.J. (eds.): ...ir a buscar leña. Estudios de- dicados al Prof. Jesús López. (Aula Aggyptiaca-Studia 2). Barcelona: 175-184.

WILKINSON, R.H.

2002 Los templos del antiguo Egipto. Barcelona (ed. orig. 2000, London).

2003 The Complete Gods and Goddesses of Ancient Egypt. London. 


\section{Trabajos de Egiptología Papers on Ancient Egypt}

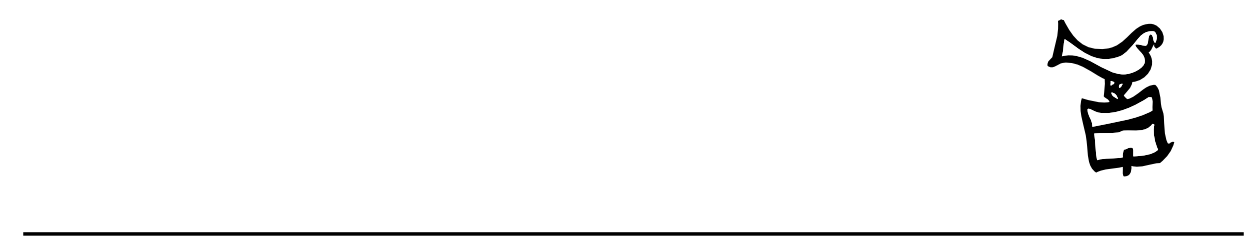

Número 5/1 2009 


\section{Actas \\ III Congreso Ibérico de Egiptología III Congresso Ibérico de Egiptologia}

Editores

Miguel Ángel Molinero Polo Covadonga Sevilla Cueva 


\title{
Editor
}

Miguel Ángel Molinero Polo

Universidad de La Laguna

\section{Consejo Editorial}

\author{
Antonio Pérez Largacha \\ Universidad de Castilla-La Mancha \\ José-R. Pérez-Accino \\ Birkbeck, Universidad de Londres \\ Covadonga Sevilla Cueva \\ Universidad Autónoma de Madrid
}

\section{Comité Científico}

Josep Cervelló i Autuori

Universitat Autònoma de Barcelona

$\mathrm{M}^{\mathrm{a}}$ José lópez Grande

Universidad Autónoma de Madrid

Josep Padró i Parcerisa

Universitat de Barcelona

$\mathrm{M}^{\mathrm{a}}$ Carmen Pérez Die

Museo Arqueológico Nacional, Madrid

Ester Pons Mellado

Museo Arqueológico Nacional, Madrid

José M. Serrano Delgado

Universidad de Sevilla

\section{Colaboradores Editoriales}

Linda Steynor

English editorial assistant

Hervé Mouriacoux

Assistant éditorial pour la langue française 
Trabajos de Egiptología está producida por Isfet. Egiptología e Historia c/ Blanco $1,2^{\circ}$

38400 Puerto de la Cruz

Tenerife-Islas Canarias

España

Maquetación: Proyecto Limón

(C) Autores de los artículos aparecidos

y Consejo Editorial de Trabajos de Egiptología - Papers on ancient Egypt

Depósito Legal: TF-2302-2009

ISSN: $1695-4750$

Imprime: Gráfica Los Majuelos, S.L.L.

imprenta@graficaslosmajuelos.com

Tfno.: 922311455 


\section{Comité Científico \\ III Congreso Ibérico de Egiptología III Congresso Ibérico de Egiptologia}

Miguel Á. Molinero Polo

Universidad de La Laguna

Presidente del Comité Organizador del III Congreso Ibérico de Egiptología

Miembro del Comité Organizador del I Encuentro de Egiptología

Josep Cervelló Autuori

Universitat Autònoma de Barcelona

Presidente del Comité Organizador del II Congreso Ibérico de Egiptologia

José Manuel Galán Allué

Consejo Superior de Investigaciones Cientificas

Director del Proyecto Djehuty, Luxor, Egipto

$\mathrm{M}^{\mathrm{a}}$ Helena Trindade Lopes

Universidad de Lisboa

Directora de la Misión Arqueológica Portuguesa en Menfis

Josep Padró i Parcerisa

Universitat de Barcelona

Director de la Misión Arqueológica de Oxirrinco

Antonio Pérez Largacha

Universidad de Castilla - La Mancha

Miembro del Comité Organizador del I Encuentro de Egiptología

José Ramón Pérez-Accino

Birkbeck College, University of London

Miembro del Comité Organizador del I Encuentro de Egiptología

$\mathrm{M}^{\mathrm{a}}$. Carmen Pérez Díe

Museo Arqueológico Nacional

Directora de la Misión Arqueológica Española en Heracleópolis Magna, Egipto

Covadonga Sevilla Cueva

Universidad Autónoma de Madrid

Miembro del Comité Organizador del I Encuentro de Egiptología 